\title{
Removal of Chromium from Aqueous Solution Using
}

\section{Yukitsubaki Carbon}

\author{
Yanling Deng ${ }^{1}$, Naoki Kano ${ }^{2 *}$, Sho Naramori ${ }^{1}$, Liang $\mathrm{Xu}^{1}$ and Hiroshi Imaizumi ${ }^{2}$ \\ 1. Graduate School of Science and Technology, Niigata University, Niigata 950-2181, Japan \\ 2. Department of Chemistry and Chemical Engineering, Faculty of Engineering, Niigata University, Niigata 950-2181, Japan
}

\begin{abstract}
Adsorption of chromium (Cr) from aqueous solution onto Yukitsubaki carbon has been investigated in a batch system. The effect of $\mathrm{pH}$, contact time and carbon dosage on the adsorption of $\mathrm{Cr}$ by Yukitsubaki carbon have been evaluated with ICP-AES (inductively coupled plasma atomic emission spectrometer) in order to obtain the optimum conditions for the Cr adsorption process. Adsorption isotherms of $\mathrm{Cr}$ onto the carbon were measured at varying initial concentrations under optimized condition. The surface properties of the carbon were characterized using $\mathrm{N}_{2}$-BET, SEM (scanning electron microscope) and FT-IR (Fourier transform infrared spectroscopy). Consequently, the following matters have been mainly clarified. (1) Yukitsubaki carbon can be an efficient sorbent for Cr, particularly for cation species Cr(III); (2) The effect of common ions on the adsorption of Cr was not significant, although the adsorption of $\mathrm{Cr}(\mathrm{VI})$ was inhibited under high concentrations of common ions; (3) Adsorption isotherms using the Yukitsubaki carbon can be generally described by Langmuir isotherm more satisfactorily for Cr. The adsorption may have occurred mainly by monolayer reaction; (4) The rates of adsorption were found to conform to pseudo-second order kinetics.
\end{abstract}

Key words: Yukitsubaki carbon, chromium, adsorption isotherms, kinetics.

\section{Introduction}

Water pollution due to heavy metal has become one of the largest problems in recent years $[1,2]$. In particular, releasing wastewater containing heavy metal poses a threat to both human health and environment $[3,4]$. The water that we drink may contain industrial wastewater with chromium [5].

Cr mainly consists of two stable oxidation states such as trivalent state $\mathrm{Cr}(\mathrm{III})$ and hexavalent state $\mathrm{Cr}(\mathrm{VI})$ in natural aqueous environment [6]. $\mathrm{Cr}(\mathrm{VI})$ may be present in the form of $\mathrm{CrO}_{4}{ }^{2-}$ or $\mathrm{HCrO}_{4}^{-}$, whereas $\mathrm{Cr}(\mathrm{III})$ tends to form $\left[\mathrm{Cr}\left(\mathrm{H}_{2} \mathrm{O}\right)_{6}\right]^{3+}$, $\mathrm{Cr}\left(\mathrm{H}_{2} \mathrm{O}\right)_{5}(\mathrm{OH})^{2+}, \mathrm{Cr}\left(\mathrm{H}_{2} \mathrm{O}\right)_{4}(\mathrm{OH})_{2}{ }^{+}$, or $\mathrm{Cr}(\mathrm{III})$ organic complexes. It is well known that $\mathrm{Cr}(\mathrm{III})$ is essential materials for living organisms, whereas $\mathrm{Cr}(\mathrm{VI})$ is more toxic, carcinogenic, and mutagenic [7-10].

Therefore the separation and reduction of chromium in waste water is very important for environmental

\footnotetext{
*Corresponding author: Naoki Kano, associate professor, research fields: environmental influence evaluation, technology and dynamic analysis. E-mail: kano@eng.niigata-u.ac.jp.
}

protection and human health [11]. Various treatment technologies such as ion exchange, precipitation, ultrafiltration, reverse osmosis and electro dialysis have been used for the removal of heavy metal ions from aqueous solution [12]. However, these processes have some disadvantages, such as high consumption of reagent and energy, low selectivity, high operational cost, and difficult further treatment due to generation of toxic sludge [13].

In recent years, biological materials as adsorbent for water purification have become a hot research topic $[14,15]$. Biological adsorbent has the advantages of recyclable, low cost, easy operation and little possibility of secondary pollution $[16,17]$.

From above-mentioned, sorption experiment of $\mathrm{Cr}$ using chitosan was performed in previous paper [18]. In this paper, the adsorption experiments for $\mathrm{Cr}$ using "Yukitsubaki" carbon (special product for Aga Town in Niigata Prefecture) have been presented as part of the adsorption study of metals using relatively low cost biomass. 
The aim of this paper is to investigate the adsorption efficiency of Yukitsubaki carbon for more practical use in the future.

Adsorption isotherms of $\mathrm{Cr}(\mathrm{Cr}(\mathrm{VI})$ and $\mathrm{Cr}(\mathrm{III}))$ were studied and analyzed using Langmuir and Freundlich equations, and kinetics analyses were also carried out. In addition, to evaluate the characteristics of the sample used in this work, the surface morphology of the carbon was determined by SEM (scanning electron microscope) and FT-IR (Fourier transform infrared spectroscopy).

\section{Experimental Sections}

\subsection{Materials and Reagents}

Yukitsubaki carbon was made from the trunk of Camellia japonica L. which grows in the northeast of Japan, a particularly special product of Aga Town in Niigata Prefecture.

Yukitsubaki carbon was pestled and sieved with 60 mesh. For the removal of ash in the carbon, deashing was carried out with boiled ultrapure water, then, it was dried at $110{ }^{\circ} \mathrm{C}$ in an oven. In addition to the pristine carbon, the carbon was oxidized in $10 \%$ $\mathrm{HNO}_{3}$ and $30 \% \mathrm{HNO}_{3}$ at $90{ }^{\circ} \mathrm{C}$ for $4 \mathrm{~h}$, respectively, and washed with ultrapure water in order to completely remove residue. Subsequently the sample was heated at $300{ }^{\circ} \mathrm{C}$ for $2 \mathrm{~h}$ to remove the residual nitrate ions on Yukitsubaki carbon.

$\mathrm{Cr}$ (III) standard solutions were prepared by diluting a standard solution $\left(1,000 \mathrm{mg} \cdot \mathrm{dm}^{-3} \mathrm{Cr}\left(\mathrm{NO}_{3}\right)_{3}\right.$ solution), and $\mathrm{Cr}(\mathrm{VI})$ standard solutions were prepared by diluting a standard solution $\left(1,000 \mathrm{mg} \cdot \mathrm{dm}^{-3} \mathrm{~K}_{2} \mathrm{Cr}_{2} \mathrm{O}_{7}\right.$ solution), which was both purchased from Kanto Chemical Co. Inc. All other chemical reagents were also purchased from Kanto Chemical Co., Inc. All reagents used were of analytical grade, and water $(>$ 18.2 $\mathrm{M} \Omega$ in electrical resistance) which was treated by an ultrapure water system (Advantec aquarius: RFU 424TA, Advantec Toyo, Japan) was employed throughout the work.

\subsection{Experiment of Apparatus}

The morphology of Yukitsubaki carbon was characterized by a SEM (JSM-5800, JEOL, Ltd.). The material was placed on a microgrid of silicon, and transferred to the analysis chamber in the SEM equipment.

The carbon was also investigated using FTIR spectroscopy (FTIR-4200, Jasco, Corporation) to identify the functional groups. For FTIR in pressed $\mathrm{KBr}$ pellets, the sample was washed three times with ethanol for $5 \mathrm{~min}$, filtered, and dried at $110^{\circ} \mathrm{C}$ for $24 \mathrm{~h}$. The spectral resolution was set to $1 \mathrm{~cm}^{-1}$, and 150 scans were collected for each spectrum.

The specific surface areas and pore volumes of Yukitsubaki carbon were measured by $\mathrm{N}_{2}$ adsorption/desorption using a surface area and pore size analyzer (TriStar II 3020, Micromeritics, Instrument Corporation) after vacuum degassing of the sample in the tube at $200{ }^{\circ} \mathrm{C}$ for $12 \mathrm{~h}$.

An ICP-MS (inductively coupled plasma mass spectrometry) instrument (ThermoFisher Scientific X2) was used to determine the concentration of $\mathrm{Cr}$.

\subsection{Sorption Experiment of $\mathrm{Cr}$ Using Yukitsubaki Carbon}

The adsorption capacities of $\mathrm{Cr}$ from aqueous solution of the Yukitsubaki carbon were investigated by a batch method. Yukitsubaki carbon was thoroughly mixed with $50 \mathrm{~cm}^{3}$ of containing known amount of $\mathrm{Cr}$ ( $\mathrm{Cr}(\mathrm{III})$ or $\mathrm{Cr}(\mathrm{VI}))$ in a $200 \mathrm{~cm}^{3}$ conical flask, and the suspensions were shaken by an automatic shaker (PLUS SHAKER EP-1, TAITEC, Corporation) in a water bath at room temperature $\left(25 \pm 2{ }^{\circ} \mathrm{C}\right)$. Sorption experiments were conducted by varying the $\mathrm{pH}$ (1-6 or 1-7), contact time (12 min to $8 \mathrm{~h}$ or $12 \mathrm{~h}$ ), sorbent dosage $\left(0.1-3.0 \mathrm{~g} \cdot \mathrm{dm}^{-3}\right)$. The $\mathrm{pH}$ of each solution was adjusted by using $0.1 \mathrm{~mol} \cdot \mathrm{dm}^{-3} \mathrm{NaOH}$ and $0.1 \mathrm{~mol} \cdot \mathrm{dm}^{-3} \mathrm{HNO}_{3}$.

Adsorption isotherms of $\mathrm{Cr}$ ( $\mathrm{Cr}$ (III) and $\mathrm{Cr}(\mathrm{VI})$ ) onto Yukitsubaki carbon were measured at varying initial $\mathrm{Cr}$ concentrations (10-200 ppb) under 
optimized conditions.

Following each sorption experiment, the suspension containing Yukitsubaki carbon and the above standard solution was filtered through a $0.45 \mu \mathrm{m}$ membrane filter (Advantec Mixed Cellulose Ester, $47 \mathrm{~mm}$ ) to remove $\mathrm{Cr}(\mathrm{III})$ or $\mathrm{Cr}(\mathrm{VI})$ that have been adsorbed into the Yukitsubaki carbon. Then the concentration of this metal in the filtrate was determined with an ICP-MS.

The metal uptake by the carbon was calculated using the following Eq. (1) [19]:

$$
q=\frac{\left(C_{0}-C_{e}\right)}{W} \cdot V
$$

where, $q$ is the adsorption capacities of $\mathrm{Cr}$ using Yukitsubaki carbon at equilibrium $\left(\mathrm{mg} \cdot \mathrm{g}^{-1}\right), C_{0}$ and $C_{e}$ are the initial and equilibrium concentrations of $\mathrm{Cr}(\mathrm{III})$ and $\mathrm{Cr}(\mathrm{VI})$ in a batch system respectively $\left(\mathrm{mg} \cdot \mathrm{dm}^{-3}\right)$, $V$ is the volume of the solution $\left(\mathrm{dm}^{3}\right)$, and $W$ is the dry weight of each adsorbent (g).

\subsection{Langmuir and Freundlich Isotherm Model}

Adsorption isotherms of sorption data were studied at varying initial concentration from 10 to $200 \mathrm{ppb}$ under optimized condition of $\mathrm{pH}$, contact time and the dosage of Yukitsubaki carbon.

Two common adsorption models, Langmuir and Freundlich isotherm model were applied to evaluate the adsorption data [20].

Langmuir model assumes monolayer sorption onto a surface and is given by Eq. (2):

$$
\frac{C_{e}}{q_{e}}=\frac{C_{e}}{q_{\max }}+\frac{1}{K_{L} q_{\max }}
$$

where, $C_{e}$ is the concentration of $\mathrm{Cr}(\mathrm{III})$ or $\mathrm{Cr}(\mathrm{VI})$ in a batch system at equilibrium $\left(\mathrm{mg} \cdot \mathrm{dm}^{-3}\right), q_{e}$ is the amount of adsorption of $\mathrm{Cr}(\mathrm{III})$ or $\mathrm{Cr}(\mathrm{VI})$ at equilibrium $\left(\mathrm{mg} \cdot \mathrm{g}^{-1}\right), q_{\max }$ is the maximum adsorption capacity on the surface of Yukitsubaki carbon $\left(\mathrm{mg} \cdot \mathrm{g}^{-1}\right)$, and $K_{L}$ is the equilibrium adsorption constant $\left(\mathrm{dm}^{3} \cdot \mathrm{mg}^{-1}\right)$. A plot of $\mathrm{C}_{e} / q_{e}$ versus $\mathrm{C}_{e}$ gives a straight line with slope of $1 / q_{\max }$, and intercept is $1 /\left(K_{L} q_{\max }\right)$. $K_{L}$ can be related to the adsorption free energy $\Delta G_{\text {ads }}$
$\left(\mathrm{J} \cdot \mathrm{mol}^{-1}\right)$ by the following Eq. (3) [21]:

$$
\Delta G_{\text {ads }}=-R T \ln K_{L}
$$

where, $R$ is the gas constant $\left(8.314 \mathrm{~J} \cdot \mathrm{K}^{-1} \mathrm{~mol}^{-1}\right), T$ is the absolute temperature at equilibrium $(K)$, and $K_{L}$ is the equilibrium constant at temperature $T$.

The equilibrium constant $K_{L}$ can be calculated from Eq. (4):

$$
K_{L}=q_{\mathrm{e}} / C_{e}
$$

where, $C_{\mathrm{e}}$ and $q_{e}$ are same as mentioned above in Eq. (2).

On the other hand, the linearized Freundlich model isotherm is represented by the following Eq. (5):

$$
\log _{10} q_{e}=\log _{10} K_{F}+(1 / n) \log _{10} C_{e}
$$

where, $K_{F}$ and $1 / n$ indicate the adsorption capacity and the adsorption intensity of the system, respectively. The plots of $q_{e}$ versus $C_{e}$ in $\log$ scale can be plotted to determine values of $1 / n$ and $K_{F}$ depicting the constants of Freundlich model.

\subsection{Kinetic Studies}

Kinetic models have been proposed to determine the mechanism of the adsorption process, which provide useful data to improve the efficiency of the adsorption and feasibility of process scale-up [22]. In the present investigation, the mechanism of the adsorption process was studied by fitting pseudo first-order and second-order reactions to the experimental data.

The pseudo first-order model is given by the following Eq. (6):

$$
\ln \left(q_{e}-q_{t}\right)=\ln \left(q_{e}\right)-k_{1} t
$$

where, $q_{e}$ and $q_{t}$ are the adsorption capacities of $\mathrm{Cr}(\mathrm{III})$ or $\mathrm{Cr}(\mathrm{VI})$ using chitosan at equilibrium and time $t$, respectively ( $\left.\mathrm{mol} \cdot \mathrm{g}^{-1}\right)$, and $k_{1}$ is the rate constant of the pseudo-first-order adsorption $\left(\mathrm{h}^{-1}\right)$.

The linear form of the pseudo second-order rate equation is given as follows:

$$
\frac{t}{q_{t}}=\frac{1}{k q_{e}^{2}}+\frac{t}{q_{e}}
$$


where, $q_{e}$ and $q_{t}$ are the adsorption capacities of $\mathrm{Cr}(\mathrm{III})$ or $\mathrm{Cr}(\mathrm{VI})$ using chitosan at equilibrium and time $t$, respectively $\left(\mathrm{mol} \cdot \mathrm{g}^{-1}\right)$, and $k$ is the rate constant of the pseudo-second-order adsorption $\left(\mathrm{g} \cdot \mathrm{mol}^{-1} \cdot \mathrm{h}^{-1}\right)$.

\section{Results and Discussion}

\subsection{Characteristics of Pristine Carbon and Modified Yukitsubaki Carbon}

The morphologies of pristine Yukitsubaki carbon and modified carbon characterized by SEM are shown in Fig. 1. Moreover, the surface properties including specific surface areas of pristine and modified Yukitsubaki carbon determined by $\mathrm{N}_{2}$-BET method are shown in Table 1. The pore structures of all the samples are similar to each other. However, judging from the SEM images in Fig. 1, the surface area of modified Yukitsubaki carbon $\left(\mathrm{HNO}_{3} 30 \%\right)$ (Fig. 1c) seems to be slightly changed with the acid treatment, whereas that of modified Yukitsubaki carbon $\left(\mathrm{HNO}_{3}\right.$ $10 \%$ ) (Fig. 1b) seems to be hardly varied. This is consistent with the data of the specific surface area in Table 1. The decrease in the specific surface area of modified Yukitsubaki carbon $\left(\mathrm{HNO}_{3} 30 \%\right)$ would be attributable to the excessive oxidation with a high concentration of nitric acid.

The FTIR spectra of pristine and modified Yukitsubaki carbon are shown in Fig. 2. From it, a characteristic broad band, which may be due to graphite structure in carbon, is observed at around $1,610 \mathrm{~cm}^{-1}$. The peak at $3,300 \mathrm{~cm}^{-1}$ is related to hydroxyl groups $(-\mathrm{OH})$, and $1,120 \mathrm{~cm}^{-1}$ is related to carbonyl groups $(-\mathrm{C}=\mathrm{O})$, and then the peaks at 2,920 and $2,850 \mathrm{~cm}^{-1}$ are associated with $\mathrm{C}-\mathrm{H}$. The results of FTIR analysis show that some kinds of functional groups (such as carbonyl groups and hydroxyl groups) are introduced to pristine carbon surfaces successfully by oxidation.

Then, the first estimation concerning the adsorption of $\mathrm{Cr}(\mathrm{Cr}(\mathrm{III})$ or $\mathrm{Cr}(\mathrm{VI}))$ on pristine Yukitsubaki carbon has been carried out at the present work.

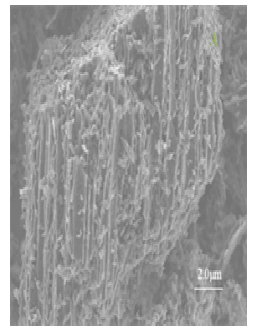

(a)

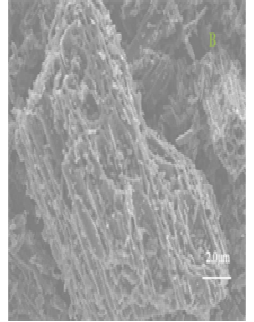

(b)

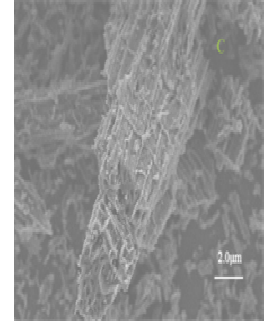

(c)
Fig. 1 The SEM images of pristine and modified Yukitsubaki carbon: (a) pristine; (b) $\mathrm{HNO}_{3} 10 \%$; (c) $\mathrm{HNO}_{3} 30 \%$.

Table 1 Surface properties of pristine carbon and modified Yukitsubaki carbon.

\begin{tabular}{|c|c|c|c|}
\hline Samples & $\begin{array}{l}\text { Specific } \\
\text { surface area } \\
\left(\mathrm{m}^{2} / \mathrm{g}\right)\end{array}$ & $\begin{array}{l}\text { Pore } \\
\text { volume } \\
\left(\mathrm{cm}^{3} / \mathrm{g}\right)\end{array}$ & $\begin{array}{l}\text { Pore size } \\
(\mathrm{nm})\end{array}$ \\
\hline $\begin{array}{l}\text { Pristine Yukitsubaki } \\
\text { carbon }\end{array}$ & 157 & 0.0854 & 2.18 \\
\hline $\begin{array}{l}\text { Modified carbon } \\
\left(\mathrm{HNO}_{3} 10 \%\right)\end{array}$ & 158 & 0.0852 & 2.16 \\
\hline $\begin{array}{l}\text { Modified carbon } \\
\left(\mathrm{HNO}_{3} 30 \%\right)\end{array}$ & 144 & 0.0774 & 2.15 \\
\hline
\end{tabular}

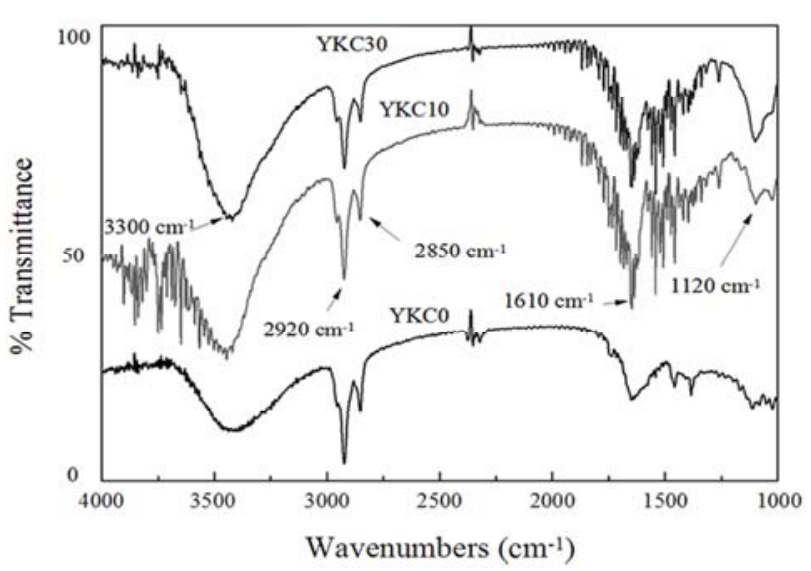

Fig. 2 The FTIR spectra of pristine and modified Yukitsubaki carbon.

In future work, the adsorption of $\mathrm{Cr}$ ( $\mathrm{Cr}(\mathrm{III})$ or $\mathrm{Cr}(\mathrm{VI}))$ on modified Yukitsubaki carbon will be examined.

\subsection{Effect of $p H$}

Solution $\mathrm{pH}$ is one of the most important parameters affecting adsorption characteristics. In case of $\mathrm{Cr}$, the dominant chemical species alter as $\mathrm{pH}$ varies [23]. In order to investigate the effects of solution $\mathrm{pH}$ on the uptake of $\mathrm{Cr}(\mathrm{III})$ or $\mathrm{Cr}(\mathrm{VI})$, sorption experiments were conducted at different $\mathrm{pH}$ values at room temperature $25{ }^{\circ} \mathrm{C}$, while the 
concentration of $\mathrm{Cr}(\mathrm{III})$ or $\mathrm{Cr}(\mathrm{VI})$ was kept constant at $100 \mathrm{ppb}$, and Yukitsubaki carbon dosage was 1.0 $\mathrm{g} \cdot \mathrm{dm}^{-3}$. The contact time was $4 \mathrm{~h}$.

The results for $\mathrm{Cr}(\mathrm{III})$ are shown in Fig. 3a. The removal rate of $\mathrm{Cr}(\mathrm{III})$ is no more than $30 \%$ at $\mathrm{pH} \leq 3$, and the removal rate of $\mathrm{Cr}(\mathrm{III})$ is more than $99 \%$ at 4 $\leq \mathrm{pH} \leq 6$. The decrease of the adsorption capacities at low $\mathrm{pH}$ may be attributable to the competition of protons with metal ions for active binding. Therefore, $\mathrm{pH}$ of 5 was taken for further experimental work.

The results for $\mathrm{Cr}(\mathrm{VI})$ are shown in Fig. 3b. The removal rate is relatively low (about 37\%) at $\mathrm{pH} 1$, however, the removal rate is $78 \%$ and $90 \%$ at $\mathrm{pH} 2$ and 3 respectively. The removal of $\mathrm{Cr}(\mathrm{VI})$ was no more than $11 \%$ at $4 \leq \mathrm{pH} \leq 7$. Thus $\mathrm{pH} 3$ was selected as the optimal $\mathrm{pH}$ for further work.

Species distribution of $\mathrm{Cr}$ at different $\mathrm{pH}$ based on theoretical calculation [24] is shown in Fig. 4. From Fig. 4a, $\mathrm{Cr}$ (III) exists predominantly as $\mathrm{Cr}^{3+}$ at $\mathrm{pH} \mathrm{1-3,}$ whereas exists predominantly as $\mathrm{CrOH}^{2+}$ at $\mathrm{pH}$ 4-6.

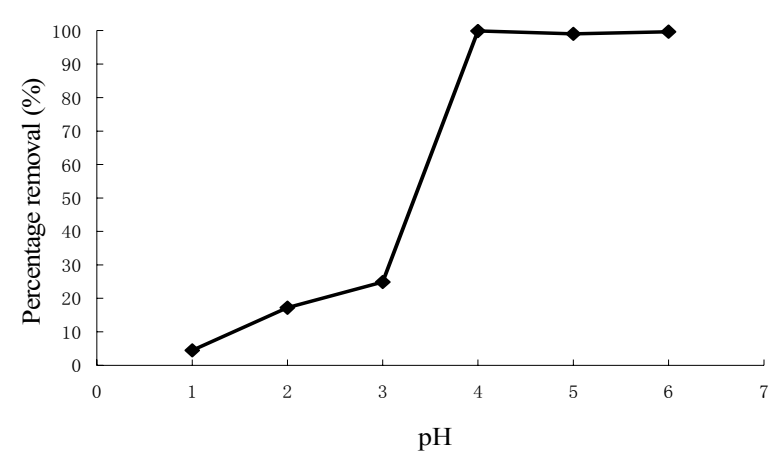

(a)
Furthermore, from the results of FTIR spectra in Fig. 2, hydroxyl groups $(-\mathrm{OH})$ are included in Yukitsubaki carbon. Then, it can be considered that the $\mathrm{Cr}$ (III) adsorption occurred dominantly by the cation exchange reaction between $\mathrm{H}^{+}$of hydroxyl groups on the carbon and the cationic species of Cr(III).

On the other hand, $\mathrm{Cr}(\mathrm{VI})$ exists as hydrogen chromate anions $\left(\mathrm{HCrO}_{4}{ }^{-}\right)$between $\mathrm{pH} 2$ and 6.5, and it exists as chromate ions $\left(\mathrm{CrO}_{4}{ }^{2-}\right)$ at $\mathrm{pH}$ above 6.5 (Fig. 4b). It is considered that this anion species has a tendency to bind to the protonated active sites of the Yukitsubaki carbon at optimum $\mathrm{pH}$.

\subsection{Effect of Contact Time}

The effect of contact time on the adsorption capacity of $\mathrm{Cr}$ (III) using $1.0 \mathrm{~g} \cdot \mathrm{dm}^{-3}$ Yukitsubaki carbon $\left(100 \mu \mathrm{g} \cdot \mathrm{dm}^{-3}\right.$ of $\mathrm{Cr}$ solution $)$ is investigated at $\mathrm{pH} 5$ at room temperature $25^{\circ} \mathrm{C}$. On the other hand, the effect of contact time on the adsorption capacity of

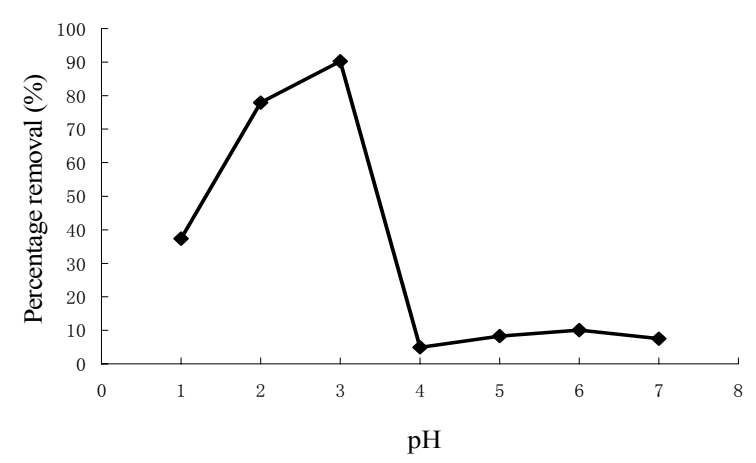

(b)

Fig. 3 Effect of pH on percent removal of $\mathrm{Cr}$ using Yukitubaki: (a) $\mathrm{Cr}$ (III); (b) $\mathrm{Cr}$ (VI).

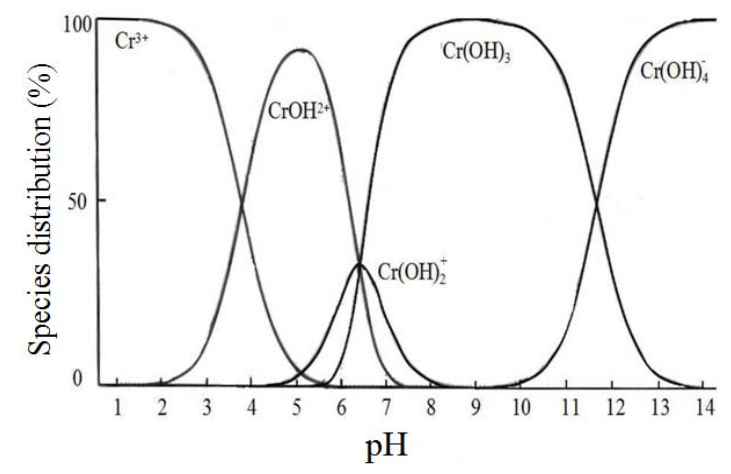

(a)

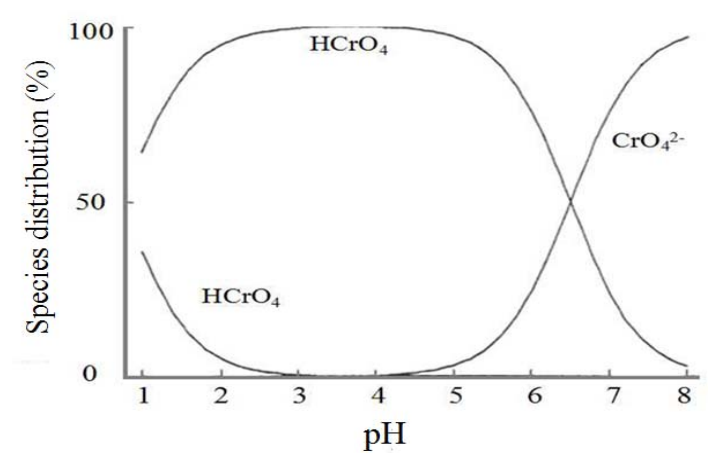

(b)

Fig. 4 Species distribution curves of $\mathrm{Cr}$ in environmental water: (a) $\mathrm{Cr}$ (III); (b) $\mathrm{Cr}$ (VI). 


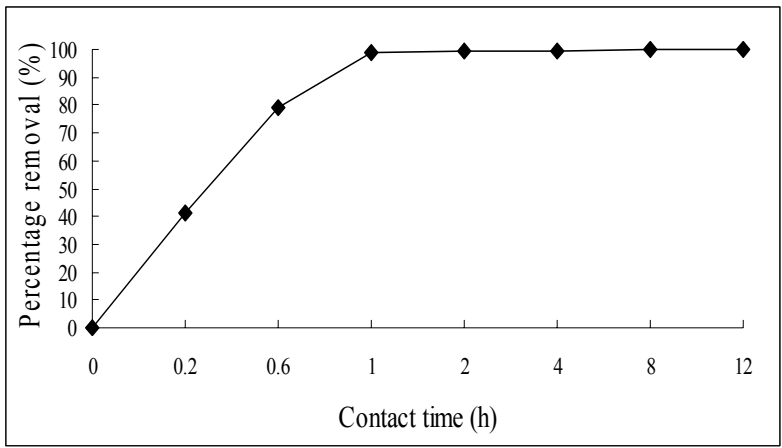

(a)

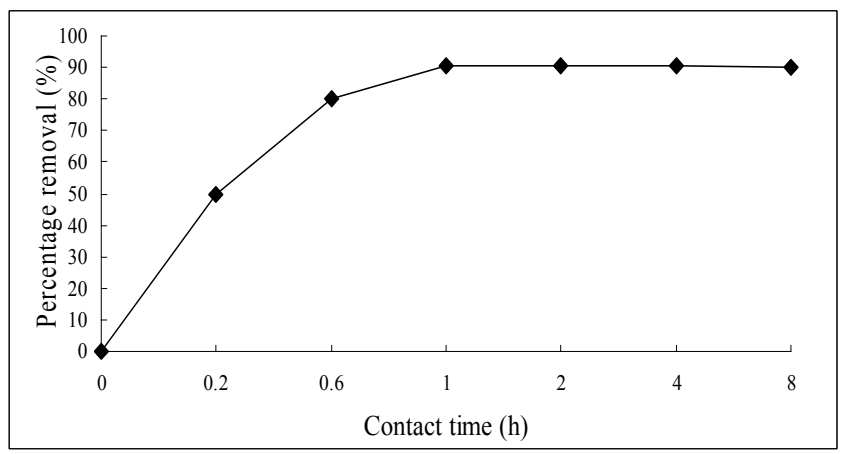

(b)

Fig. 5 Effect of contact time on percent removal of $\mathrm{Cr}$ using Yukitubaki: (a) $\mathrm{Cr}$ (III); (b) $\mathrm{Cr}$ (VI).

Cr(VI) using $1.0 \mathrm{~g} \cdot \mathrm{dm}^{-3}$ Yukitsubaki carbon (100 $\mu \mathrm{g} \cdot \mathrm{dm}^{-3}$ of solution) is investigated at $\mathrm{pH} 3$.

The adsorption capacity of Yukitsubaki carbon for $\mathrm{Cr}$ (III) reached adsorption equilibrium at $1 \mathrm{~h}$, and after that there is no appreciable change (Fig. 5a). In case of $\mathrm{Cr}(\mathrm{VI})$ removal, more than $90 \%$ adsorption was observed within first $1 \mathrm{~h}$, and after that there is no appreciable increase (Fig. 5b). Hence, the optimized contact time was chosen $2 \mathrm{~h}$ for $\mathrm{Cr}$ (III) and $1 \mathrm{~h}$ for $\mathrm{Cr}(\mathrm{VI})$, respectively for the rest of the experimental work.

\subsection{Effect of Yukitsubaki Carbon Dosage}

Under optimized condition of $\mathrm{pH}$ and contact time, sorption behavior of Yukitsubaki carbon at different dosages from 0.1 to $3.0 \mathrm{~g} \cdot \mathrm{dm}^{-3}$ have been studied in $100 \mathrm{ppb}\left(\mu \mathrm{g} \cdot \mathrm{dm}^{-3}\right)$ of $\mathrm{Cr}$ solution. The removal of Cr(III) more than $98 \%$ was observed for $1.0 \mathrm{~g} \cdot \mathrm{dm}^{-3}$ dosage (Fig. 6a). The removal of $\mathrm{Cr}(\mathrm{VI})$ more than $93 \%$ was observed for $0.5 \mathrm{~g} \cdot \mathrm{dm}^{-3}$ dosage (Fig. $6 \mathrm{~b}$ ), but no remarkable increase is observed at a dosage more than $0.5 \mathrm{~g} \cdot \mathrm{dm}^{-3}$. Therefore, $1.0 \mathrm{~g} \cdot \mathrm{dm}^{-3}$ was considered as optimum dosage for $\mathrm{Cr}$ (III), and $0.5 \mathrm{~g} \cdot \mathrm{dm}^{-3}$ was considered for $\mathrm{Cr}(\mathrm{VI})$, respectively for the rest of the study.

\subsection{Adsorption Isotherms}

Adsorption isotherms are commonly used to reflect the performance of adsorbents in adsorption processes. The adsorption data obtained for $\mathrm{Cr}$ ( $\mathrm{Cr}$ (III) and Cr(VI)) using Yukitsubaki carbon were analyzed by
Langmuir and Freundlich equations. The correlation coefficient $\left(R^{2}\right)$ of these isotherms for $\mathrm{Cr}$ (III) and $\mathrm{Cr}(\mathrm{VI})$ on the carbon is shown in Table 2 along with other relevant parameters.

From Table 2, it is found that $R^{2}$ value for $\mathrm{Cr}$ (III) and $\mathrm{Cr}(\mathrm{VI})$ is comparatively large, and favorable adsorption of $\mathrm{Cr}$ by the carbon was presented. Particularly, $R^{2}$ values in Langmuir isotherm are large for both $\mathrm{Cr}(\mathrm{III})$ and $\mathrm{Cr}(\mathrm{VI})$. This result suggests that the adsorption of $\mathrm{Cr}$ on Yukitsubaki carbon mainly occurred by monolayer reaction.

\subsection{Kinetic Studies}

The results for kinetic studies are shown in Fig. 9. From Fig. 9, it is observed that the rates of adsorption were found to conform to pseudo-second order equation than pseudo first-order equation. Based on the data in Fig 9, the pseudo second-order kinetic coefficients for $\mathrm{Cr}(\mathrm{III})$ and $\mathrm{Cr}(\mathrm{VI})$ by Yukitubaki carbon are estimated (Table 3 ). The rate constant of second-order equation $(k)$ diffusion are $2.94 \times 10^{-2}$ $\mathrm{g} \cdot \mathrm{mol}^{-1} \cdot \mathrm{h}^{-1}$ for $\mathrm{Cr}$ (III) and $3.40 \times 10^{-2} \mathrm{~g} \cdot \mathrm{mol}^{-1} \cdot \mathrm{h}^{-1}$ for $\mathrm{Cr}(\mathrm{VI})$. The correlation coefficients were more than 0.99 for both $\mathrm{Cr}(\mathrm{III})$ and $\mathrm{Cr}(\mathrm{VI})$ adsorption on Yukitubaki carbon.

\subsection{Effect of Competitive Ions on the Sorption of $\mathrm{Cr}$}

3.7.1 Effect of Competitive Cations $\left(\mathrm{Na}^{+}, \mathrm{K}^{+}, \mathrm{Ca}^{2+}\right.$ and $\mathrm{Mg}^{2+}$ ) on the Sorption of $\mathrm{Cr}(\mathrm{III})$.

Competitive experiment for $\mathrm{Cr}$ (III) was conducted at optimized $\mathrm{pH}(\mathrm{pH} 5)$, contact time $(2 \mathrm{~h})$ and sorbent 


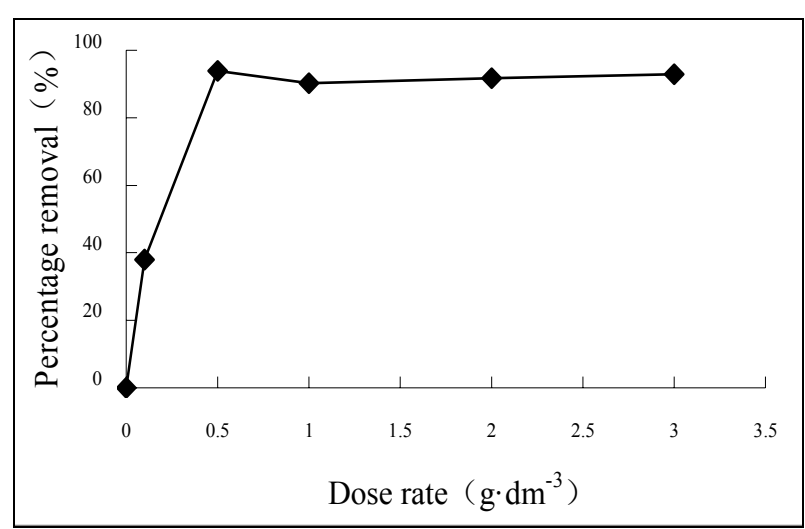

(a)

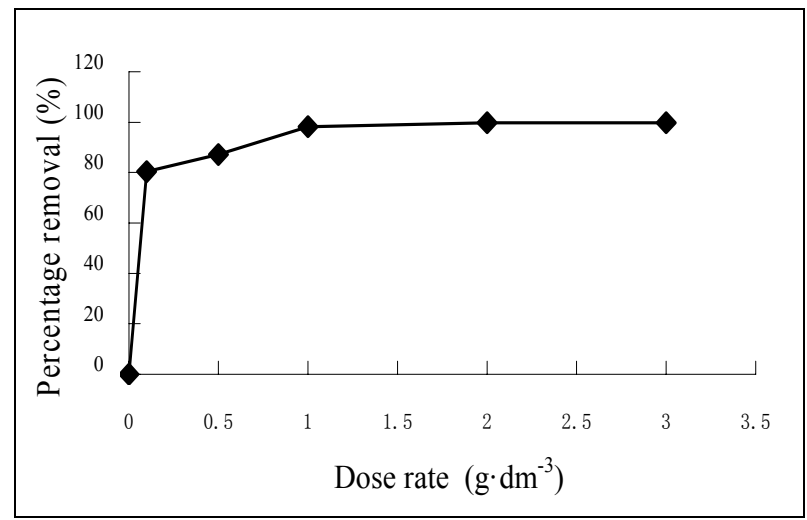

(b)

Fig. 6 Effect of dose rate on percent removal of Cr using Yukituba: (a) Cr(III); (b) Cr(VI).

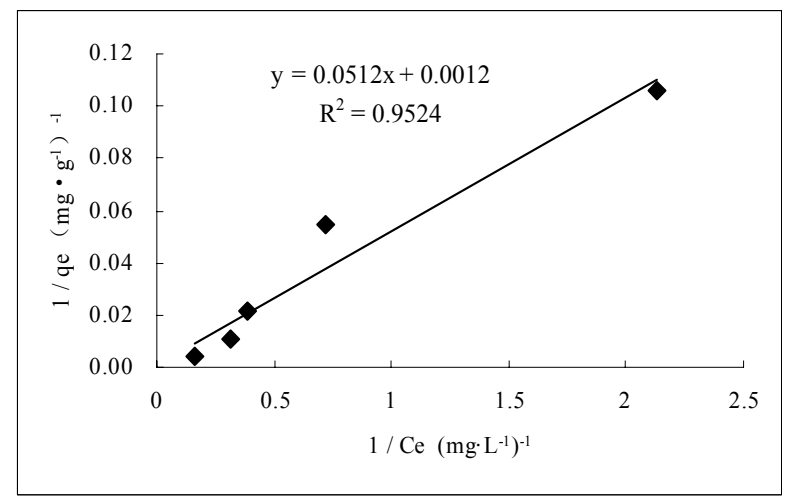

(a)

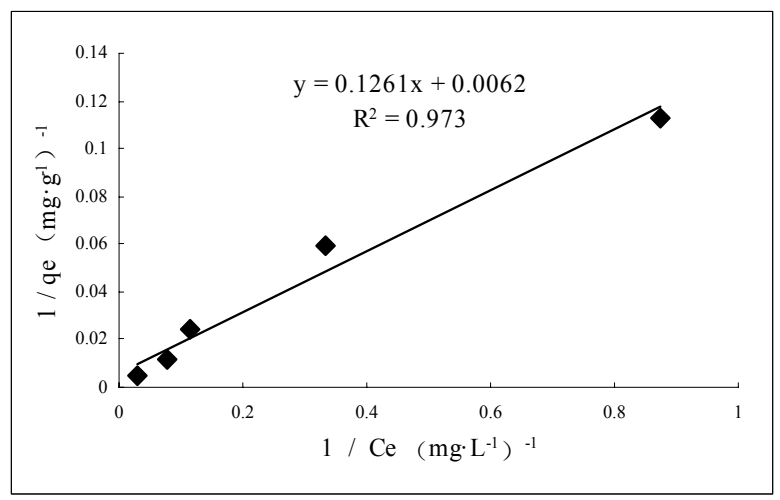

(b)

Fig. 7 Langmuir liner fit of batch sorption data for Yukitubaki: (a) Cr(III); (b) Cr(VI).

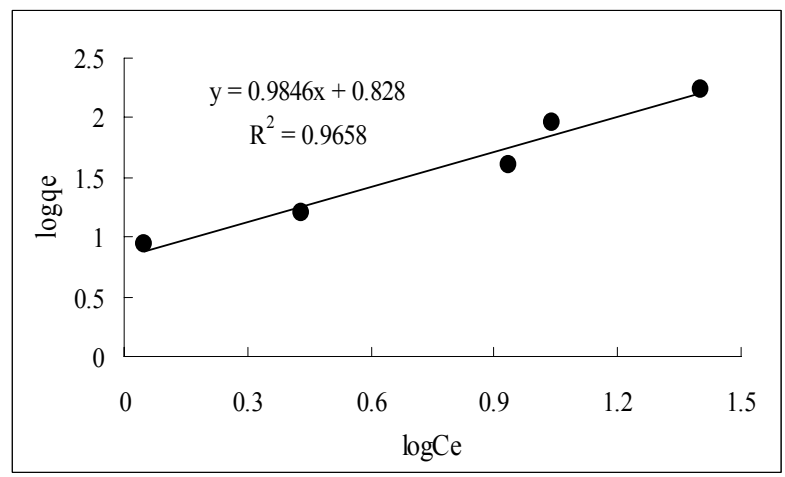

(a)

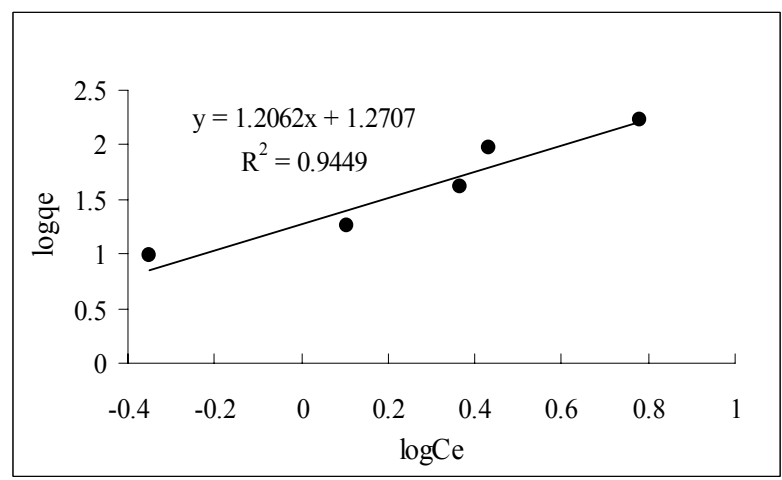

(b)

Fig. 8 Freundlich liner fit of batch sorption data for Yukitubaki: (a) $\mathrm{Cr}$ (III); (b) Cr(VI).

Table 2 Coefficient of Langmuir and Freundlich isotherms for $\mathrm{Cr}(\mathrm{Cr}$ (III)and $\mathrm{Cr}$ (VI)) using Yukitubaki.

\begin{tabular}{lllllll}
\hline & \multicolumn{5}{c}{ Langmuir isotherm } & \multicolumn{2}{c}{ Freundlich isotherm } \\
\cline { 2 - 7 } & $\begin{array}{l}q_{\max } \\
\left(\mathrm{mg} \cdot \mathrm{g}^{-1}\right)\end{array}$ & $\begin{array}{l}K_{L} \\
\left(\mathrm{dm}^{3} \cdot \mathrm{g}^{-1}\right)\end{array}$ & $\mathrm{R}^{2}$ & $\begin{array}{l}\mathrm{K}_{\mathrm{F}} \\
\left(\left(\mu \mathrm{g} \cdot \mathrm{g}^{-1}\right)\right. \\
\left.\left(\mathrm{dm}^{-3} \cdot \mu \mathrm{g}^{-1}\right)^{1 / n}\right)\end{array}$ & $1 / \mathrm{n}$ & $\mathrm{R}^{2}$ \\
\hline $\mathrm{Cr}(\mathrm{III})$ & $1.81 \mathrm{E}-01$ & $1.94 \mathrm{E}+01$ & 0.952 & 18.6 & 0.826 & 0.945 \\
$\mathrm{Cr}(\mathrm{VI})$ & $9.96 \mathrm{E}-02$ & $2.21 \mathrm{E}+02$ & 0.973 & 6.73 & 0.967 & 0.967 \\
\hline
\end{tabular}




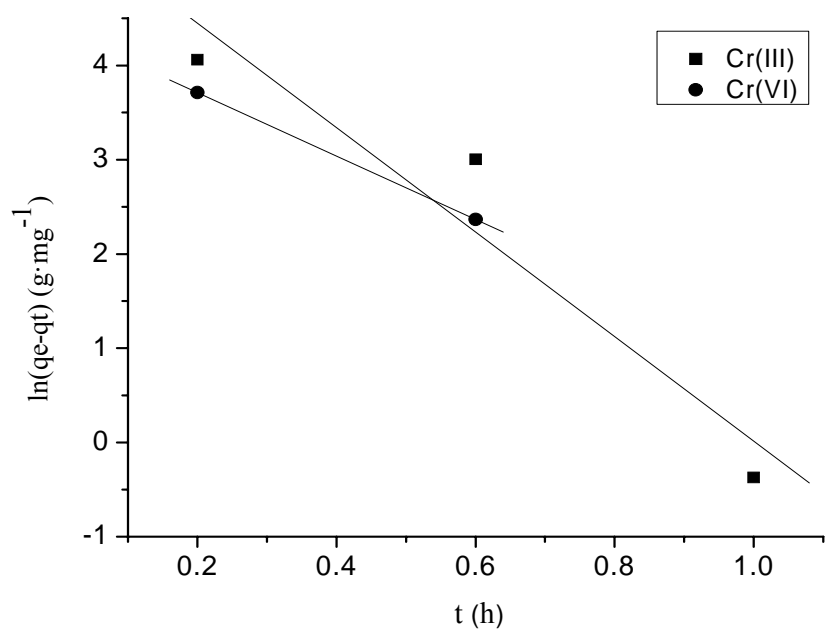

(a)

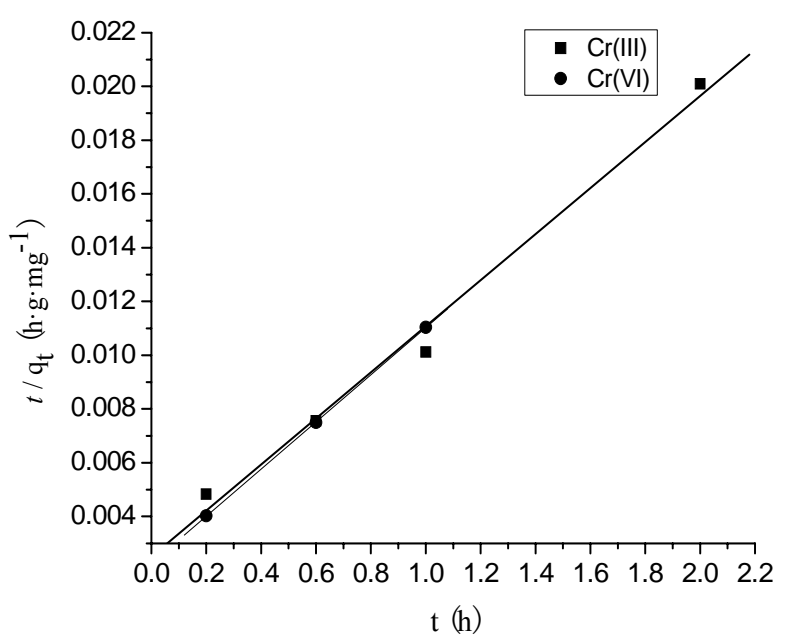

(b)

Fig. 9 The kinetic model on Yukitubaki: (a) the pseudo first -order kinetic model; (b) the pseudo second-order kinetic model.

Table 3 The pseudo second-order kinetic coefficient for $\mathrm{Cr}$ (III) and $\mathrm{Cr}$ (VI) using Yukitubaki carbon.

\begin{tabular}{llll}
\hline & $\begin{array}{l}q_{\mathrm{e}} \\
\left(\mathrm{mg} \cdot \mathrm{g}^{-1}\right)\end{array}$ & $\begin{array}{l}k \\
\left(\mathrm{~g} \cdot \mathrm{mol}^{-1} \cdot \mathrm{h}^{-1}\right)\end{array}$ & $R$ \\
\hline $\mathrm{Cr}(\mathrm{III})$ & 0.117 & $2.94 \times 10^{-2}$ & 0.994 \\
$\mathrm{Cr}(\mathrm{VI})$ & 0.114 & $3.40 \times 10^{-2}$ & 0.999 \\
\hline
\end{tabular}

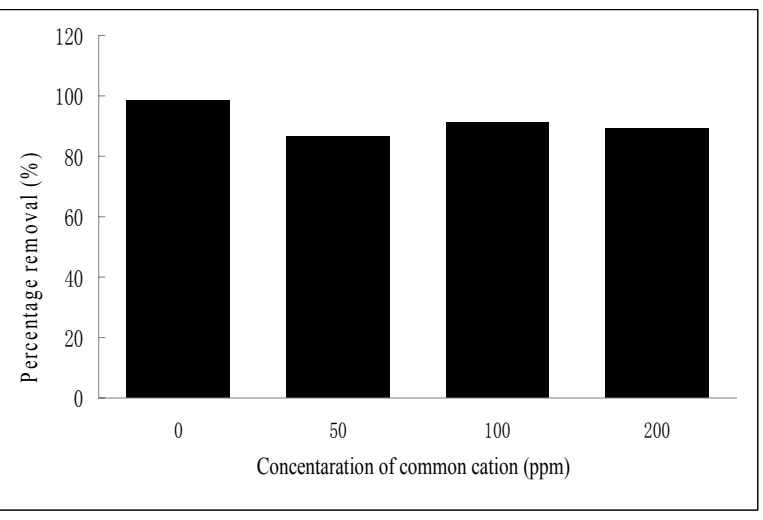

(a)

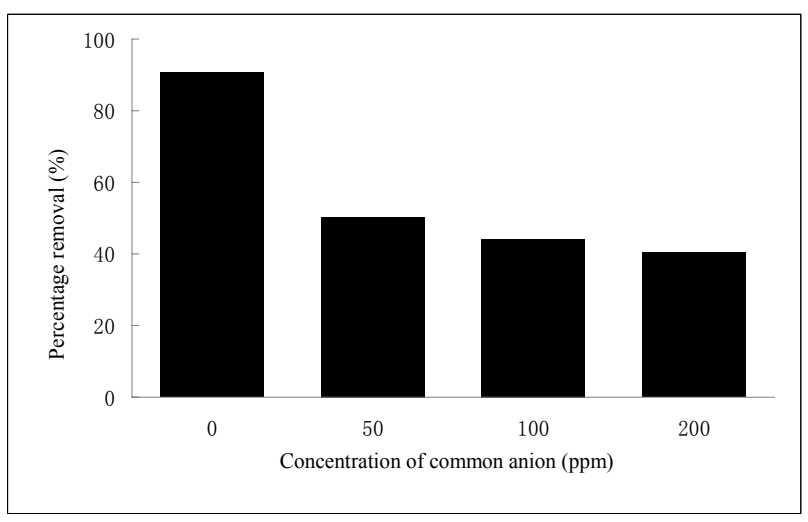

(b)

Fig. 10 Effect of common ion on percent removal of $\mathrm{Cr}$ using Yukitubaki carbon: (a) $\mathrm{Cr}$ (III); (b) $\mathrm{Cr}$ (VI).

dosage $\left(1 \mathrm{~g} \cdot \mathrm{dm}^{-3}\right)$ under the presence of common ions $\left(\mathrm{Na}^{+}, \mathrm{K}^{+}, \mathrm{Ca}^{2+}\right.$ and $\left.\mathrm{Mg}^{2+}\right)$ at different concentrations 0 , 50, 100 and 200 ppm (Fig. 10a). It is found that the remarkable decrease of sorption capacity of $\mathrm{Cr}$ (III) was not observed, even if the concentrations of common ions are $200 \mathrm{ppm}$.

3.7.2 Effect of Competitive Anions $\left(\mathrm{Cl}^{-}, \mathrm{NO}_{3}{ }^{-}\right.$and $\mathrm{SO}_{4}{ }^{2-}$ ) on the Sorption of $\mathrm{Cr}(\mathrm{VI})$

Competitive experiment for $\mathrm{Cr}(\mathrm{VI})$ was performed at optimized $\mathrm{pH}(\mathrm{pH} 3)$, contact time (1 h) and sorbent dosage $\left(0.5 \mathrm{~g} \cdot \mathrm{dm}^{-3}\right)$ under the presence of common ions $\left(\mathrm{Cl}^{-}, \mathrm{NO}_{3}{ }^{-}\right.$and $\left.\mathrm{SO}_{4}{ }^{2-}\right)$ at different concentrations 0 , 50, 100 and 200 ppm (Fig. 10b). In case of sorption capacity of $\mathrm{Cr}(\mathrm{VI})$, the decrease of removal (40-50\%) was observed when the concentrations of common ions are 50-200 ppm.

From Figs. 10a and 10b, it is suggested that the sorption of $\mathrm{Cr}$ (III) on Yukitsubaki carbon was fairly good under this experimental condition. It indicates that Yukitsubaki carbon can be an efficient adsorbent for $\mathrm{Cr}$ (III) in aqueous environment, although it requires further investigations for applying the carbon 
to use as an adsorbent for heavy metal more practically.

\section{Conclusions}

The efficiency of Yukitsubaki carbon as an adsorbent for $\mathrm{Cr}$ (Cr(III) and $\mathrm{Cr}(\mathrm{VI}))$ was investigated. From this work, the following matters were clarified:

(1) Yukitsubaki carbon exhibited high adsorption capacity for $\mathrm{Cr}$. The removal of $\mathrm{Cr}$ (III) was more than $99 \%$, and the removal of $\mathrm{Cr}(\mathrm{VI})$ was more than $90 \%$ under this optimal experimental conditions;

(2) The effect of common cations $\left(\mathrm{Na}^{+}, \mathrm{K}^{+}, \mathrm{Ca}^{2+}\right.$ and $\mathrm{Mg}^{2+}$ ) on the adsorption of $\mathrm{Cr}$ (III) was not significant up to concentrations of $200 \mathrm{ppm}$. On the contrary, the effect of common anions $\left(\mathrm{Cl}^{-}, \mathrm{NO}_{3}{ }^{-}\right.$and $\mathrm{SO}_{4}{ }^{2-}$ ) on the adsorption of $\mathrm{Cr}(\mathrm{VI})$ was rather large up to the concentration of 50-200 ppm;

(3) $\mathrm{Cr}(\mathrm{III})$ and $\mathrm{Cr}(\mathrm{VI})$ adsorption on the Yukitsubaki carbon conforms to the Langmuir isotherm adsorption equation, and the correlation coefficients are more than 0.95 and 0.97 , respectively. The maximum adsorption capacity of $\mathrm{Cr}$ (III) and $\mathrm{Cr}(\mathrm{VI})$ on chitosan calculated by the Langmuir model were $1.81 \times 10^{-1}$ and $9.96 \times 10^{-2} \mathrm{mg} \cdot \mathrm{g}^{-1}$, respectively;

(4) The best fit was obtained with a pseudo-second order kinetic model while investigating the adsorption kinetics, and the correlation coefficients were both more than 0.99 for $\mathrm{Cr}(\mathrm{III})$ and $\mathrm{Cr}(\mathrm{VI})$.

From these results, it was quantitatively clarified to some extent that Yukitsubaki carbon can be an efficient sorbent for $\mathrm{Cr}$ (particularly for $\mathrm{Cr}$ (III)), which provide very significant information from the viewpoint of environmental protection.

\section{Acknowledgements}

The present work was partially supported by a Grant-in-Aid for Scientific Research (Research Program (C), No. 25340083) of the Japan Society for the Promotion of Science. This research was also supported by a Fund for promotion of Niigata University KAAB Projects from the Ministry of
Education, Culture, Sports, Science and Technology, Japan.

The authors are also grateful to Dr. K. Fujii and Mr. M. Ohizumi of Office for Environment and Safety in Niigata University, Mr. N. Saito and Mr. T. Hatamachi of Fac. of Eng. in Niigata University for permitting the use of ICP-AES, SEM and Surface Area Analyzer, and for giving helpful advice in measurement.

\section{References}

[1] Peng, G., Tian, G., Liu, J., Bao, Q., and Zang, L. 2011 "Removal of Heavy Metals from Sewage Sludge with a Combination of Bioleaching and Electrokinetic Remediation Technology." Desalination 271: 100-4.

[2] Yesim, S., and Tul, K. 2000. "Determination of the Biosorption Heats of Heavy Metal Ions on Zoogloea Ramigera and Rhizopus Arrhizus." Biochemical Engineering Journal 6: 145-51.

[3] Zewail, T. M., and Yousef, N. S. 2014. "Chromium Ions $\left(\mathrm{Cr}^{6+}\right.$ and $\left.\mathrm{Cr}^{3+}\right)$ Removal from Synthetic Wastewater by Electrocoagulation Using Vertical Expanded Fe Anode." Journal of Electroanalytical Chemistry 735: 123-8.

[4] Alaerts, G. J., Jitjaturant, V., and Kelderman, P. 1989. "Use of Coconut Shell Based Activated Carbon for Chromium (VI) Removal." Water Science and Technology 21: 1701-4.

[5] Prakashamrs. 1999. "Biosorption of Chromium (VI) by Free and Immobilized Rhizopus Arrhizus." Water Treatment Technology 104: 421-7.

[6] Zhao, H., Liao, X., and Zhou, Z. Q. 2011. "Study on the Adsorption of Modified Peanut Shell for $\mathrm{Cr}^{6+}$ in Wastewater." Applied Chemical Industry 40: 78-84.

[7] Donais, M. K., Henry, R., and Rettberg, T. 1999. "Chromium Speciation Using an Automated Liquid Handling System with Inductively Coupled Plasma-Mass Spectrometric Detection.” Talanta 49: 1045-50.

[8] Acosta, R. I., Rodriguez X., Gutierrez C., and Guadalupe, M. M. 2004. "Biosorption of Chromium (VI) from Aqueous Solutions onto Fungal Biomass." Bioinorganic Chemistry and Application 2: 1-7.

[9] Mungasavalli, D. P., Viraraghavan, T., and Jin, Y. C. 2007. "Biosorption of Chromium from Aqueous Solutions by Pretreated Aspergillus Niger: Batch and Column Studies." Colloids and Surfaces, Physicochemical and, Engineering Aspects 301: 214-23.

[10] Hakan, D., Demiral, I., Fatma, T., and Belgin, K. 2008. "Adsorption of Chromium from Aqueous Solution by Activated Carbon Derived from Olive Bagasse and 
Applicability of Different Adsorption Models." Chemical Engineering Journal 144: 188-96.

[11] Fendorf, S. E. 1995. "Surface Reaction of Chromium in Soils and Waters." Geoderma 67: 55-71.

[12] Fu, F., and Wang, Q. 2011. "Removal of Heavy Metal Ions from Wastewater: A Review." Journal of Environmental Management 92: 407-18.

[13] Rahmati, M. M., Rabbani, P., Abdolali, A., and Keshtkar, A. R. 2011. "Kinetics and Equilibrium Studies on Biosorption of Cadmium, Lead, and Nickel Ions from Aqueous Solutions by Intact and Chemically Modified Brown Algae." Journal of Hazardous Materials 185: 401-7.

[14] El-Enany, A. E., and Issa, A. A. 2000. "Cyanobacteria as a Biosorbent of Heavy Metals in Sewage Water." Environmental Toxicology and Pharmacology 8 (2): 95-101.

[15] Nurbas, M., and Nourbakhsh, S. 2002. "Biosorption of $\mathrm{Cr}^{6+}, \mathrm{Pb}^{2+}$, and $\mathrm{Cu}^{2+}$ Ions in Industrial Wastewater on Bacillus." Chemical Engineering Journal 85: 351-5.

[16] Albadarin, A. B., Mangwandi, C., Walker, G. M., and Allen, S. J. 2012. "Influence of Solution Chemistry on $\mathrm{Cr}$ (VI) Reduction and Complexation onto Date-pits/Tea-waste Biomaterials." Journal of Environmental Management 114: 190-201.

[17] Kobya, M. 2004. "Removal of $\mathrm{Cr}(\mathrm{VI})$ from Aqueous Solutions by Adsorption onto Hazelnut Shell Activated Carbon: Kinetic and Equilibrium Studies." Bioresource Technology 91: 317-21.
[18] Kano, N., Tanabe, K., Pang, M. L., Deng, Y. L., and Imaizumi, H. 2014. "Biosorption of Chromium from Aqueous Solution Using Chitosan.” J. Chem. Chem. Eng. 8: 1049-58.

[19] Ahmad, B. A., Yang, Z. Y., and Chirangano, M. W. 2014. "Experimental Design and Batch Experiments for Optimization of $\mathrm{Cr}(\mathrm{VI})$ Removal from Aqueous Solutions by Hydrous Cerium Oxide Nanoparticles." Chemical Engineering Research and Design 92: 1354-62.

[20] Selvi, K., Pattabin, S., and Kadirvelu, K. 2001. "Removal of $\mathrm{Cr}(\mathrm{VI})$ from Aqueous Solutions by Adsorption onto Activated Carbon." Bioresource Technology 80: 87-9.

[21] Albadarin, A. B., Mangwandi, C., Al-Muhtaseb, A. A. H., Walker, G. M., and Allen, S. J. 2012. "Kinetic and Thermodynamics of Chromium Ions Adsorption onto Low-cost Dolomite Adsorbent." Chemical Engineering Journal 179: 193-202.

[22] Mohammadi, M., Hassani, A. J., Mohamed, A. R., and Najafpour, G. D. 2010. "Removal of Rhodamine B from Aqueous Solution Using Palm Shell-based Activated Carbon: Adsorption and Kinetic Studies." Journal of Chemical and Engineering Data 55: 5777-85.

[23] Kousalya, G. N., Gandhi, M. R., and Meenakshi, S. 2010. "Sorption of Chromium (VI) Using Modified Forms of Chitosan Beads." International Journal of Biological Macromolecules 47: 308-15.

[24] Irgolic, K. J., Greschonig, H., and Howard, A. G. 1999. Encyclopedia of Analytical Science. Vol. 1, 729-43. New York: Academic Press. 